\title{
Higienismo e ações de remodelamento urbano no Recife (1900-1929)
}

Hygiene and actions of urban remodeling in Recife (1900-1929)

\author{
Marcos Alessandro Neves*
}

Palavras-chave:

Higienismo

Modernidade

Recife

Keywords:

Hygiene

Modernity

Recife

\begin{abstract}
Resumo: Recife no início do século XX, assim como outras capitais do Brasil, enfrentou diversas mudanças em seu aspecto paisagístico, demolição de casarões antigos, remoção de populações carentes de áreas habitadas há vários anos para dar lugar a empreendimentos imobiliários com a proposta de modernização e embelezamento da cidade. Dessa forma, o presente artigo tem como intuito analisar como o discurso modernizante foi utilizado com o intuito de promover obras de viés higienistas, que almejavam a exclusão da população que ocupava esses espaços, atendendo aos anseios de uma elite local que clamava por uma cidade tida como moderna para os seus conceitos.
\end{abstract}

Abstract: Recife at the beginning of the 20th century, as well as other Brazilian capitals, faced several changes in its landscape aspect, demolition of old mansions, removal of populations deprived of inhabited areas several years ago to give rise to real estate developments with the proposal of modernization and beautification of City. Thus, the present article aims to analyze how the modernizing discourse was used to promote works of hygienist bias, which aimed at the exclusion of the population that occupy these spaces, attending to the wishes of a local elite who calls for a city held as modern for its concepts.

Recebido em 28 de outubro de 2017. Aprovado em 28 de dezembro de 2017.
Um dos temas mais abordados pela historiografia brasileira são as ações de remodelamento urbano com viés higienista que ocorreram de forma intensa no final do século XIX e no início do XX. A ciência histórica, juntamente com a história da arquitetura e do urbanismo, mostra a relação existente entre a arquitetura e a cidade como palco dos acontecimentos históricos em diversos momentos. Com o advento da arquitetura moderna, que abandona os fins primordialmente estéticos do século XIX (COSTA, 1962), as cidades passam por uma nova concepção atrelada às preocupações com as epidemias e a falta de saneamento. A Belle Époque, entre os anos de 1870 e 1914, foi responsável pelo crescimento de importantes centros urbanos como Londres e Paris, capitais que serviram de inspiração para diversas cidades brasileiras.

A diferença econômica seria um fator importante que marcou as ações de remodelamento urbano que ocorreram na Europa e as que aconteceram pelas capitais brasileiras. Enquanto a França de Hausmann ${ }^{1}$ modificou de forma intensa sua arquitetura, no Brasil houve encontros com a modernidade ${ }^{2}$ que começavam em uma rua, mas que não resistiam ao bairro mais próximo, por conta da ausência de recursos.

Recife enfrentou no início do século XX, diversas mudanças em seu aspecto paisagístico: demolição de casarões antigos e remoção de populações carentes de áreas habitadas há vários anos para dar lugar a empreendimentos imobiliários com a proposta de modernização e embelezamento da cidade.

Remodelar as cidades embelezá-las, destituí-las de suas feições coloniais, eram, todas essas, palavras de ordem de grande aceitação e repercussão nos jornais, revistas, conversas em cafés etc.

\footnotetext{
* Mestre em História pela Universidade Federal da Paraíba, graduado em História pela Universidade Estadual de Pernambuco e professor da rede particular de ensino em Recife. Desenvolve pesquisas no campo da história social do trabalho, tendo como objeto as vilas operárias. E-mail: <marcos.alessandro.neves@hotmail.com>.
} 
Não apenas no Rio de Janeiro. Várias outras cidades brasileiras passaram por processos semelhantes de reformas urbanas, tendo sempre a justificá-las o discurso modernizador característico. (TEIXEIRA, 1994, p. 13).

Tais empreendimentos modificaram de forma intensa a vida da população, em especial das classes mais baixas. O discurso modernizante propunha uma cidade com largas avenidas, parques arborizados e casarões modernos para que a elite recifense pudesse desfrutar, assim como aqueles que estavam apenas visitando a capital a negócios (REZENDE, 1987). A cidade moderna, entendida como salubre e uniforme do ponto de vista estético, "com ruas alinhadas, construções suntuosas e pobres expulsos das áreas centrais, começava a ser gestada" (TEIXEIRA, 1994, p. 33).

Recife, no início do século XX, estava envolvida em projeto de modernização e expansão do centro da cidade, engenheiros e arquitetos de várias vertentes debatiam a arquitetura moderna e o urbanismo que buscavam solucionar os problemas que assolavam todas as grandes cidades brasileiras. Em relação às alterações no bairro do Recife, foi vista uma ampla intervenção arquitetônica financiada pela iniciativa privada, com o amparo do governo estadual, dando respaldo às intervenções que, consequentemente, proporcionaram uma valorização financeira da área remodelada, transformando também os hábitos e costumes daqueles que habitavam a região e repelindo aqueles que não se adaptavam aos novos tempos, sendo este o ponto central deste artigo.

As atividades humanas mais animalescas são progressivamente excluídas do palco da vida comum e investidas de sentimentos de vergonha, que a regulação de toda a vida instintiva e afetiva por um firme autocontrole se torna cada vez mais estável, uniforme e generalizada. (ELIAS, 1993, p. 193- 194).

Por "palco da vida", sugerido acima por Elias, podemos fazer uma analogia com as cidades que "flertavam" com os ventos de modernidade, os hábitos tidos como animalescos, atrelados a classe pobre, tinha o desprezo das elites que não almejavam dividir as mesmas praças, os mesmos bancos, os mesmos espaços. Por conta da ausência de políticas públicas que fossem capazes de produzir uma inserção da população pobre que habitava a capital pernambucana, era comum que vendedores ambulantes, prostitutas, e menores abandonados estivessem em situação de vulnerabilidade, ocasionando problemas que iam de epidemias a problemas com a polícia. $^{3}$

O centro do Recife, no final do século XIX e início do XX, foi o "abrigo" dessa população que se amontoava em casebres e cortiços, dividindo espaços minúsculos com várias famílias, o que para as elites representava o risco eminente de doenças contagiosas, frutos dos "maus hábitos"4. Era do interesse das elites econômicas que essas pessoas estivessem em lugares afastados do centro, pois, possuiam hábitos tidos como animalescos, que em nada corroboravam com a imagem moderna que se almejava.

Com o respaldo das teorias higienistas, foi possível implantar uma perseguição àqueles que eram tidos como transmissores de mazelas sociais. Mendigos, prostitutas, e todos aqueles que não possuíam trabalho formal e habitavam o centro, que moravam em cortiços ou mocambos, formavam o grupo das "classes perigosas", que foram forçadas a ocupar lugares longe do centro, considerado civilizado e, agora, lugar moderno da cidade.

Tais teorias tiveram seu início na Europa, no século XIX, devido às doenças e epidemias que grassavam entre as populações das grandes cidades. Com a industrialização das grandes cidades da Europa, os centros urbanos tiveram um aumento populacional muito grande o que causou uma precariedade nas condições de higiene (ARRAIS, 2004). As teorias higienistas, amparadas pela medicina social, tão em voga na Europa, embasaram a construção de uma imagem moderna do Recife. Sendo assim, os médicos passariam a procurar nos hábitos e costumes dos cidadãos mais pobres a razão para as epidemias que assolavam os centros urbanos propondo em seguida o tratamento, que ia da vacinação em massa à desodorização do espaço urbano. 
Milhares de pessoas deslocando-se para o desempenho do ato cotidiano na vida das grandes cidades compõem um espetáculo que, na época, incitou ao fascínio e ao terror. Gestos automáticos e reações instintivas em obediência a um poder invisível modelam o fervilhante desfile de homens e mulheres e conferem à paisagem urbana uma imagem frequentemente associada às ideias de caos, de turbilhão, de ondas, metáforas inspiradas nas forças incontroláveis da natureza. (BRESCIANI, 1990, p. 10).

Medidas como essa tinham o intuito de regular os costumes da população pobre que não estava conectada aos anseios da modernidade. Sendo assim, o higienismo promoveu não só mudanças de caráter urbanístico, mas também mudanças de caráter moral na população. A insalubridade era terreno fértil para proliferação de doenças que representavam um medo para as elites locais. Dessa forma, o ar e a água ${ }^{6}$ eram analisados constantemente com o intuito de impedir a transmissão de doenças e pestes como a cólera e a tuberculose que assolavam todo o estado.

Com essa nova concepção de higiene, a rua e a casa (o público e o privado) passaram a ser alvo das investidas governamentais. Ruas largas, aterramento de pântanos, esgotamento sanitário e as casas que outrora eram "fechadas" para a rua, passam a ter janelas que modificam sua estrutura arquitetônica. Com o advento da arquitetura moderna nas grandes capitais brasileiras, exigiamse ambientes com maior luminosidade. O saber médico e dos engenheiros sanitaristas teve grande importância nas construções das casas e nos novos traçados que a cidade iria receber e a influência desses profissionais se fez presente durante todo o período das intensas modificações urbanas.

Continuando a ser de difícil solução o problema das habitações operárias e não podendo, em bem da salubridade pública, permanecer por mais tempo os mocambos actualmente existentes na Capital e nos subúrbios. Sem que se evite a promiscuidade, a falta de ar, as aglomerações nocivas nas habitações, não poderemos combater a mortalidade infantil e a tuberculose. A h-ygiene das casas populares, o seu typo, o espaço, o ar respirável são condições imprescindíveis para a solução do grande problema. (CHERMONT, 1909, p. 601).

A citação acima retrata muito bem a preocupação com a moradia operária, sendo objeto de atenção do primeiro congresso médico de Pernambuco que ocorreu em 1906. Os mocambos e as demais habitações operárias, como os antigos sobrados com precárias condições de ventilação e saneamento, eram tidos como a origem dos problemas que afetavam a cidade, portanto, durante toda primeira metade do século $\mathrm{XX}^{7}$, a casa operária será alvo das investidas higienistas. Além da abordagem higienista presente no discurso acima, é importante destacar a intenção de ter um maior controle sobre a vida das classes baixas propondo, através da moradia, um modelo de vida que venha a combater não apenas as doenças contagiosas, mas também a promiscuidade, tida como um dos "maus hábitos" atrelados à classe operária.

Disciplinar as classes populares como um todo significava controlar a criminalidade no entender das elites. Desta forma, atividades que estivessem associadas ao "não trabalho" eram alvo da polícia recifense caracterizando assim um combate à figura do vadio. Era acusado de vadiagem todo aquele cidadão, em geral preto e pobre, que não possuísse bens materiais e que tirasse o seu sustento de atividades não regulares, como gasoseiros, engraxates entre outros que não possuíam emprego fixo.

Os vagabundos, mendigos validos e hebrios habituais, vadios e desordeiros (...). Tornar-se-ão úteis a si próprios e a sociedade, que não deve ter em seu seio indivíduos ociosos e prejudiciais, e sim segregá-los em local onde deixem de constituir ameaça a coletividade ${ }^{8}$. (JORNAL DO COMÉRCIO, 16 de agosto de 1923, p. 7).

Ao contrário da apropriação atual do termo, a imagem do vadio não estava remetida apenas à ociosidade, visto que a imoralidade também fazia parte desse imaginário, pois, no entender 
das elites, a vadiagem (ócio) representava a porta para que os vícios que degeneram o ser humano pudessem adentrar. A dita vadiagem estava entre as contravenções no código penal da República, datado de 1890, onde "ser" vadio consequentemente recaía sobre as classes populares, homens pobres livres, que tinham o azar de não serem senhores de escravos e a sorte de não os ser.

Sendo assim, os ditos vadios seriam facilmente reconhecidos, fosse pela sua cor (negra) fosse por seus costumes e sua linguagem, tida como ofensiva.

Hontem, as 7 e meia horas da noite, pouco mais ou menos, o subdelegado capitão Agnello, da Boa Vista, encontrando um creoulo muito bêbado na rua da Imperatriz, ordenou a duas praças que o levassem para a detenção e retirou-se. $\mathrm{Na}$ ausência desta autoridade os dois soldados praticara revoltante barbaridade com o creoulo, que não podia caminhar devido ao seu estado de embriaguez e teve de ser arrastado, em vez de ser conduzido em padiola convenientemente amparado. Os policiaes seguraram-lhe os dois pés e puxaram-n’o sobre o calçamento, quebrando a cabeça do infeliz e ferindolhe as costas nas pedras. Ao chegar na ponte o pobre homem, bastante ensangüentado, não suportou mais os horrores do transporte, e gritou que já estava quase á morte. $\mathrm{O}$ facto attrahiu a attenção de muitas pessoas, que se aglomeraram manifestando a sua reprovação áquella selvageria, mas os soldados, aos quais já se haviam reunido outros, affirmaram que a policia não seria desautorada e que o ébrio havia de seguir assim mesmo. E assim mesmo foi conduzido até a detenção, onde deve ter chegado em condições lastimaveis. Alem d'isso um individuo, que se julga auxiliar da policia n'aquella freguesia, dirigiu-se a um grupo que protestava contra o acto de crueldade posto em pratica, e, em termos provocantes, ameaçou com uma faca de ponta a quem desejasse enfrental-o. Apresentaram-se diversos e o valentão teve de guardar a arma e sahir cabisbaixo, acompanhado pelo molecorio, que lhe deu uma solemne vaia. O capitão Agnello deve recomendar um pouco de humanidade e prudência aos seus subordinados. (A Província, 25 de maio de 1902, p. 31)

A citação acima deixa transparecer a forma que a população pobre do Recife era tratada pelas forças coercitivas. Bêbados, prostitutas e ambulantes eram "inimigos" a ser combatidos por conta de suas posturas "desviantes", embriaguez e roupas "indecorosas". Para as elites que comandavam a capital pernambucana, as ditas "classes perigosas" que habitavam o agora "moderno" centro da cidade deveriam estar sob a vigilância da polícia, ou preferencialmente situadas nos subúrbios, longe dos novos parques, das ruas arborizadas (LOPES, 2003).

A forma de abordar e de "resolver" o problema no que tange ao menor de idade e a presença de mendigos nas ruas do centro do Recife são as mesmas, pois parte-se do pressuposto que ambos estão encaixados no grupo dos sujeitos indesejáveis, sujeitos que não combinam com uma cidade que se propunha moderna, com carros em alta velocidade, cafés e parques arborizados, largas avenidas que serviam de passarela para as elites demonstrarem sua elegância e refinamento. A mendicância e os menores abandonados eram os representantes da selvageria, sendo que a única forma possível de retirá-los desse meio e incutir-lhes os preceitos da nova urbe seria através do trabalho.

Um problema que se apresentava para as elites locais, e consequentemente para a polícia, era a prostituição, pois, ao contrário da vadiagem, combatê-la não significava excluí-la de vez da capital pernambucana (COUCEIRO, 2007). A prostituição de baixo meretrício ${ }^{9}$ traz ao centro do debate higienista as famosas pensões, uma vez que eram os locais utilizados geralmente para as práticas amorosas e onde as meretrizes alugavam os quartos para poderem receber seus clientes, tornandose assim ambientes aglutinadores de pessoas e ideias que poderiam soar como ameaça aos novos preceitos da elite recifense.

Combater a prostituição não significava necessariamente retirá-la de vez da paisagem recifense, tanto que o código penal de 1890, em vigência nas primeiras décadas do século $\mathrm{XX}$, não tratava diretamente desta temática. Sendo assim, 
o intuito da polícia passava mais pelo caráter de controle desta atividade de forma que não ferisse a moral e os bons costumes cultuados pela elite da capital, sendo essa prática permitida como forma de garantir o "divertimento" dos homens da alta sociedade para que pudessem, saciar seus instintos sexuais sem macular o nome e a reputação de alguma "menina de família".

Solicito que v.exc. se digne de recomendar ao major inspetor da guarda civil que mande instruir aos guardas destinados ao policiamento neste distrito, a respeito da repressão aos hábitos deponentes de alguns rapazes viciados e os escândalos de certas hetaíras recalcitrantes e despudoradas. É ordem terminante desta delegacia proibir a qualquer meretriz a estar sentada a porta de sua residência e manter-se em conversa com indivíduos que as procuram, porque essas decaídas nunca se portam convenientemente aos nossos costumes. (JORNAL DO COMMERCIO, 1921, p. 4).

No entanto, a historiadora Sylvia Costa Couceiro, em seu artigo A sedução da noite nos cafés do Recife dos anos 1920: entre prazeres e transgressões, analisa de que forma os homens da elite se "relacionavam" com a prostituição em seus espaços. O Café Chile, localizado na Praça da Independência, área central da capital pernambucana, era tido, no início do século XX, como um espaço que abrigava uma pequena parcela mais abastada da sociedade.

Funcionando até às duas horas da manhã, suas noites eram animadas por uma orquestra que se apresentava diariamente. $\mathrm{O}$ estabelecimento era iluminado a luz elétrica, e tinha "copa à vista do freguês", podendo ser inspecionada pela clientela, demonstrando que essa deveria ser composta de pessoas exigentes quanto aos padrões de higiene e limpeza dos locais que freqüentavam. O Café possuía em seu interior uma tabacaria que dispunha para comercialização, segundo os anúncios, de cigarros, charutos e fumos de diversas procedências, o que demonstrava a preocupação em agradar os fumantes mais exigentes $\mathrm{O}$ cardápio da casa também sugeria que sua freguesia era formada de indivíduos mais abastados. Visando agradar os mais diversos paladares, o menu oferecia uma variada gama de petiscos, que iam desde refeições ligeiras, como "macarronada à italiana, ovos quentes e fritos e comidas frias", até guloseimas mais sofisticadas, como "sorvetes, refrescos, chocolates, bombons, chá, café, torradas", passando por um amplo sortimento de bebidas, que incluíam "grogs, cervejas, champagne, whisky e bebidas de todas as qualidades". A divulgação na imprensa de um cardápio diferenciado, que oferecia aos clientes alimentos e bebidas mais refinados e dispendiosos, nos leva a pensar que o Café Chile buscava atrair um público mais requintado, tentando passar, através da imprensa, a imagem de um estabelecimento moderno, confiável e com ambiente seleto. (COUCEIRO, 2007, p. 7).

Tais fatos não passavam despercebidos pelos jornais da época, que estampavam os mais variados acontecimentos em suas páginas com as chamadas "filhas de Vênus", "Camélias" ou "Filhas de Jerusalém", nomes dados às prostitutas da época. Várias são as queixas feitas pelas autoridades, que encontram na imprensa uma perfeita caixa de ressonância para suas insatisfações. Os jornais abrem suas páginas para registrar o dia a dia das mulheres que ganhavam seu sustento ou aumentavam seus ganhos com o seu corpo. Com os títulos mais diversos, entre eles a "estatística mundana", os juízos de valor estão presentes, desviando o jornalista da sua função de apurar notícias relevantes à população e tornando-o um mero especulador da vida alheia.

A imprensa da época retratava as situações envolvendo prostitutas com cenários de conflitos, violência e distúrbios sociais causados por ciúmes e crimes envolvendo meretrizes e clientes que não pagavam o que havia sido acordado anteriormente e também cafetões que exploravam mais do que as mulheres poderiam aguentar. Era comum que comportamentos tidos como imorais pela sociedade da época fossem alvo das investidas da polícia recifense. Sua linguagem, por vezes chula 
e sua roupa tida como vulgar feriam os brios da sociedade que buscava se equiparar aos preceitos europeus de civilidade e aformoseamento.

Controlar a prostituição fazia parte do plano de controle das classes pobres, em especial os homens que buscavam tal serviço. Associadas à prostituição, estavam características tidas pelas elites como perigosas, como uma vida desregrada, confusões, o vício do álcool e jogos que poderiam soar como ameaça ao operário ordeiro e sadio almejado pelas vilas operárias e assim desviá-lo de sua "sagrada missão". As vilas pregavam um ambiente de disciplina em sintonia com o que era exigido dentro das fábricas. Sendo assim, a polícia tentava, através de métodos coercitivos, restringir o raio de ação das prostitutas de baixo meretrício, regulando o horário de funcionamento de pensões e demais estabelecimentos que servissem para esse fim.

Dessa forma, o combate não dizia respeito à prostituição de forma ampla e irrestrita. As "camélias" que atendiam as classes populares, os operários e os demais trabalhadores pobres das cidades é que despertavam a atenção das autoridades policiais. $\mathrm{O}$ vocabulário tido como indecente e as vestes "vulgares" representavam o problema a ser combatido por alguns setores da elite recifense. Como diz Rago (1991, p. 294) sobre a prostituição ligada às classes populares "adquiria todo um caráter de sordidez maldita, de descontrole desenfreado, de excesso dionisíaco que assustava as classes privilegiadas".

No entanto, mesmo com tentativas constantes de cerceamento da liberdade desses grupos, a polícia não conseguiu atenuar o medo e o incômodo que as elites sentiam perante os grupos que atentavam diariamente contra a nova perspectiva de cidade moderna, higiênica e ordeira (ROSA, 2003). Além da prostituição, problemas como a mendicância e o consumo de álcool atormentavam as elites e eram motivos de preocupação para esses grupos que temiam os problemas que vinham na esteira trazida pela embriaguez das classes populares. Seguindo essa perspectiva, homens ou mulheres alcoolizados estariam mais propensos a ofender a moral, a praticar atos teoricamente não praticados em estado tido como normal.
Com os ventos da modernidade passando pela cidade do Recife, o aumento do custo de vida também sofreu um impacto importante e isso se refletiu no preço dos alugueis dificultando as já precárias condições de vida das classes populares. A crise chegou a tal ponto que, no início da década de 1920, sob o governo de Eduardo Lima de Castro, algumas medidas contra o aumento no preço da moradia receberam atenção especial, entre elas a criação de um bairro com casas que atendessem às necessidades das classes baixas e que não tivessem um alto custo.

Uma notícia alviçareira para a nossa população, que luta actualmente contra a crise das habitações, não pode ser a que, hoje, registramos, isto é, a construção de um outro bairro novo. A iniciativa do illustre sr. Coronel Lima Castro deve-se o futuro bairro do Derby, cujos estudos estão quase terminados para o início das obras. À iniciativa particular, ou melhor, à iniciativa de um moço intelligente, rico e operoso, vamos dever o bairro da Estancia. (JORNAL PEQUENO, 1921, p. 12).

A moradia tornou-se um alvo do governo e da prefeitura da cidade do Recife, a habitação proletária foi, ao longo da primeira metade do século XX, alvo de constantes investidas no sentido de combate a uma casa insalubre e que, no entender das elites, deteriorava quem a habitasse (MOREIRA, 1995). Em 1907, a moradia foi tema do Congresso Médico em Pernambuco, os mocambos e os casebres em que residiam as classes populares passam a ser tema de várias discussões por parte de médicos sanitaristas e engenheiros, que "elegem" a moradia popular como uma ameaça à saúde pública e irradiadora de todas as pestes e doenças que acometiam os moradores da cidade. Nesse congresso, o renomado médico Octavio de Freitas, responsável pela luta contra a tuberculose no estado de Pernambuco, detalha o seu estudo que visa combater a doença que era responsável pela maior parte dos óbitos na região.

Comprehendi que não podia adiar por mais tempo a execução do meu 
projecto e fiz publicar em Junho de 1900 um folheto sob o titulo A tuberculose no Recife onde, por meio de dados estatisticos, eu tornava patente a grande mortalidade da tuberculose entre nós, mostrava por meio de mappas graphicos como ella occupava o primeiro logar entre as molestias zymoticas, produzindo por si só, quazi a metade da totalidade dos obitos. Fiz tambem um estudo comparativo entre a sua mortalidade entre nós e em outras cidades quer nacionaes, quer estrangeiras e por fim apresentei as medidas a adoptar para a attenuação dos seus effeitos lethaes, tendo em começo enumerado as causas de sua frequencia excessiva entre nós. (FREITAS, 1909, p. 25 apud PEREIRA, 2013).

A concepção dessas casas foi um plano das elites recifenses, respaldado pelas teorias higienistas que davam aval para as intenções disciplinares que eram o objetivo dessas moradias que, por sua vez, representavam um mecanismo de controle do tempo do operário. O intuito de instaurar as vilas operárias era diminuir não apenas a insalubridade, mas frear os "maus hábitos" que corrompiam sua índole (PEREIRA, 2013). Era objetivo das elites despertar na classe proletária, através de uma casa limpa e salubre, o gosto pela família, o apreço pelo descanso e a vida regrada, ou seja, incutir no trabalhador operário o mesmo modelo de vida burguês. $\mathrm{O}$ modelo de vida burguês iria dificultar o acesso aos "vícios e tentações" que as ruas do centro do Recife poderiam oferecer (álcool, prostituição, brigas), pois estando longe destas tentações o operário iria render mais e melhor na escala produtiva, seria o operário idealizado pela classe burguesa, sadio e ordeiro.

Os mucambos são edificados em logares humidos, aterrados quasi sempre com lixo e cercados de pantanos e alagadiços, invadindo as aguas das grandes marés o interior de muitos delles. Seu material de construcção é composto de latas velhas ou pedaços de caixões para as paredes e capim, palha e folha de zinco para a coberta. O chão não tem revestimento algum e a divisão interna, quando existe, é a seguinte: - uma sala de frente, uma alcova sem ar e sem luz, onde dormem amontoadas tres e mais pessoas, uma sala de jantar e ao mesmo tempo cosinha e, num pequeno pateo posterior, uma fossa fixa constituida por um barril enterrado no solo. Isto nos mucambos que a possuem, porque em muitos, os despejos são feitos na maré que passa perto ou encostada á habitação. (FREITAS, 1909, p. 54 apud PEREIRA, 2013).

De acordo com os saberes higienistas da época, as vilas operárias seriam as melhores habitações para os trabalhadores operários uma vez que atenderiam suas necessidades no que diz respeito às melhores condições de salubridade. Os padrões de higiene eram o foco desses profissionais em sua "cruzada" contra as doenças e os "maus hábitos" da população pobre que, no entender desse grupo, estaria mais suscetível à contaminação por doenças venéreas, ou mesmo a tuberculose e a malária que faziam vítimas por todo o estado.

A influência imoral da sujeira e do desconforto nunca foi suficientemente levada em consideração. Esta influência é antissocial no mais alto grau, o estado miserável de sua casa é uma das causas essenciais que conduz um homem a gastar seu dinheiro em prazeres egoístas: ele entra em casa esgotado, aspira à tranquilidade, tem necessidade de repousar: a sujeira, a miséria, o desconforto sob todas as formas $o$ cercam, ele só deseja então ir embora, se puder. (TEIXERA, 2001, p. 6).

Os cortiços, mocambos e demais moradias das classes populares, bem como seus moradores, representavam entraves ao progresso e à modernidade desejada, pois estavam localizados nos espaços que as elites queriam embelezar e higienizar, ou seja, tornar moderna a área central da cidade, que seria a "sala de estar" daqueles que viessem visitar a capital recifense.

Há na cidade homens e crianças sem profissão certa e sem residência, e toda a gente sabe que a miséria e o vício geram-se um ao outro [...] É no meio destes que o alcoolismo se espalha vitoriosamente contaminando o lar miserável, sem conforto e sem higiene, 
atingindo como um polvo hediondo a mulher e os filhos. (DIÁRIO DE PERNAMBUCO, 1921, p. 3 apud ROSA, 2003).

Alguns nomes marcaram de forma expressiva esse momento de constantes modificações urbanas na cidade do Recife. Entre eles podemos citar o médico Amaury de Medeiros e o engenheiro Saturnino de Brito. Ambos promoveram em Recife, contando com o respaldo dos governantes e da elite, modificações urbanas que ansiavam uma mudança de hábitos dos cidadãos (MOREIRA, 1995). Amaury de Medeiros trabalhou como médico na gestão do governador Sérgio Loreto (1922-1926) e via a função que iria assumir não apenas na esfera médica, receitando medicamentos aos pacientes enfermos. Seu raio de ação iria extrapolar as fronteiras do consultório e iria incidir sobre uma tentativa de controle sobre as classes populares, identificando quais medidas de cunho sanitário e profiláticas seriam úteis para sanar o que considerava o foco de todas as doenças, os hábitos dos mais pobres.

Amaury era o genro do governador de Pernambuco no período de 1922-1926. Neste período, contando com o respaldo e carta branca do governador para suas ações higienistas, empreende contra as classes populares uma concepção de corpo doente a ser medicado. Dessa forma, desejava "limpar" a cidade de todas as marcas de epidemias, doenças contagiosas e venéreas. Os discursos de Amaury de Medeiros eram veiculados nos jornais de grande circulação da capital pernambucana e continham um apelo de "guerra" contra a insalubridade e, por vezes, uma tentativa de catequizar os "infiéis".

É verdade que não temos uma massa subterrânea em ebulição, mas, 'uma massa de doentes e ignorantes, como afirmou uma vez o governador do Estado. Esta massa acabará por ter uma visão deformada de nossos princípios e se poderá movimentar, com todos os inconvenientes de sua ignorância e violência. (JORNAL DO COMÉRCIO, 1923, p. 15).

Amaury de Medeiros se formou no Rio de Janeiro, onde morou até o ano de 1922, quando veio a
Recife a convite de Sérgio Loreto assumir a diretoria de Saúde e Assistência do Recife (MOREIRA, 1995). Na capital pernambucana, gozou de prestígio e confiança por parte das elites urbanas. Com seu poder à frente da diretoria, demonstrava através de discursos e atos a forma enérgica com que tratava a questão da insalubridade que acometia o a cidade. Seu poder era tamanho que, acima da diretoria de higiene a qual era diretor, só devia explicações ao governador, Sérgio Loreto, que também era seu sogro.

Já o engenheiro sanitarista Saturnino de Brito, esteve em Recife de 1910 a 1917, e foi responsável pela grande obra sanitária da capital pernambucana até então, instalando uma extensa rede de esgoto e água encanada. Francisco Saturnino Rodrigues de Brito nasceu em 14 de julho de 1864, no município de Campos, no Rio de Janeiro, vindo a falecer em 10 de março de 1929, no Rio Grande do Sul, enquanto vistoriava obras de saneamento que ele projetara para algumas cidades daquele estado.

Pode-se encontrar em Saturnino de Brito uma visão globalizante do espaço urbano que repudiava operações de redesenho estético urbano em escala pontual que intervinham apenas em partes da cidade. Procurava, sim, planejar o conjunto da cidade adotando o planejamento como meio de garantir o desenvolvimento harmônico desta. Em seus projetos de saneamento sempre ressaltava a necessidade de previsão do crescimento das cidades [...]. Brito colocava como inadiável a obrigação de prever a expansão da rede sanitária e dos arruamentos, tanto no caso das cidades planas como no caso das cidades acidentadas. (MOREIRA, 1992, p. 18).

Diante dos fatos expostos, pode-se concluir que as modificações urbanas que ocorreram em Recife estavam atreladas não apenas a um ideal de beleza arquitetônica ligada à Belle Époque e às mudanças que ocorreram na Europa. As elites locais, além do desejo de rompimento com um passado que estava relacionado ao Império e ao escravismo, viam a necessidade de pôr a sua região na rota da modernidade, do belo. Tais discursos 
trouxeram em seu bojo questões ligadas à higiene e, consequentemente, a uma perseguição àqueles que eram tidos como ameaças ao novo modelo de cidade que se almejava.

\section{Notas}

1 Hausmann propunha um embelezamento estratégico, onde as concepções arquitetônicas estariam atreladas às questões de segurança, dessa forma foram demolidas inúmeras pequenas vias estreitas oriundas do período medieval, substituindo-as por imensos jardins e parques. BENJAMIN, Walter. Paris, a capital do século XIX. In: Passagens.

2 Compartilho a visão de modernidade de Marshall, que em sua obra analisa a modernidade como um paradoxo entre ser revolucionário e conservador ao mesmo tempo, pois sente a segurança dos avanços técnico/científicos que foram alcançados, porém não possui domínio sob essas questões. Daí sua insegurança diante da imprevisibilidade do que não pode controlar. BERMAN, Marshall. Tudo que é Sólido Desmancha no Ar; São Paulo, Cia das Letras, 1988.

3 Sobre os problemas que as classes populares enfrentaram com as autoridades policiais na capital pernambucana, muito devido aos seus hábitos, que eram tidos pelas elites governamentais e os setores de segurança, como “indesejáveis", ver mais: (LOPES, 2003).

4 Para Margareth Rago, uma das formas de combater os possíveis riscos que são atrelados às classes populares, é o combate à casa dita imunda, que para as elites são os focos de das epidemias, dos vícios e da insubordinação (RAGO, 1987).

$5 \mathrm{Na}$ concepção utilizada por Chalhoub, as classes perigosas têm sua grande parcela composta pelas classes populares, seus vícios e seus hábitos somam-se para dar "luz" aos malfeitores (CHALHOUB, 1996).

6 A teoria dos miasmas afirma que uma das formas de ter o ar e as águas em estado saudável, é limpando o espaço urbano preservando o ar e as águas dos odores originários da decomposição de matéria orgânica, das casas mal construídas e das pessoas com doença contagiosa (CORBIN, 1987).

7 As investidas do estado sobre a moradia operária não cessaram nas duas primeiras décadas do século XX, nos anos 30 e durante todo o período ditatorial do Estado Novo a casa operária foi centro das atenções do estado culminando com uma "cruzada" contra os mocambos implantados pelo então interventor Agamenon Magalhães (GOMINHO, 2007).

8 De acordo com RAGO (1991) a representação do que viria ser o baixo meretrício, enfatiza o aspecto de uma animalidade, de uma sexualidade que afronta a moral burguesa. Seria então um mal a ser extirpado, uma vez que ameaçavam os esforços da elite em higienizar a cidade.

9 Sobre as nomenclaturas dadas às prostitutas, ver mais: SOUZA, Antônio Clarindo Barbosa de. Lazeres permitidos, prazeres proibidos: sociedade, cultura e lazer em Campina Grande (1945-1965); UFPE, Recife, 2002 Doutorado em História.

\section{Referências}

ARRAIS, Raimundo. O pântano e o riacho: a formação do espaço público no Recife do século XIX. São Paulo: HUMANITAS/ FFLCH/USP, 2004.

BRESCIANI, Ma Stella. Londres e Paris no Século XIX: o espetáculo da Pobreza. Coleção Tudo é História. São Paulo, Brasiliense, 1990.

COSTA, Lúcio. Sobre arquitetura. Porto Alegre: Centro de Estudantes Universitários de Arquitetura, 1962.

ELIAS, Norbert. O processo civilizador: uma história dos costumes. Rio de Janeiro: Zahar, 1993.

FREITAS, Octavio. A luta anti-tuberculosa em Pernambuco. In: Annaes do $1^{\circ}$ Congresso Médico de Pernambuco. Recife: Officina Typographica do Diario de Pernambuco, 1909.

LOPES, Gustavo Acioli. A cruzada modernizante e os infiéis no Recife, 1922-1926. UFPE, 2003

MOREIRA, Fernando Diniz. A formação do urbanismo moderno no Brasil: as concepções do engenheiro Saturnino de Brito. Recife: UFPE, 1995.

PEREIRA, Tiago Francisco. Habitação popular, reforma urbana e periferização no Recife, 19201945. UFPE, 2013.

RAGO, Margareth. Do cabaré ao lar: a utopia da cidade disciplinar, Brasil 1890-1930. 2. ed. Rio de Janeiro: Paz e Terra, 1987.

REZENDE, Antonio Paulo de Morais. Cadernos de história: manifestações operárias e socialistas em Pernambuco. Recife: UFPE, 1987. 
ROSA, Ana Lúcia Gonçalves. Passos cambaleantes, caminhos tortuosos: beber cachaça, prática social e masculinidade- Recife/PE 1920-1930. Dissertação (Mestrado em Historia) - UFC/CE, 2003.

TEIXEIRA, Flávio Weinstein. As cidades enquanto palco da modernidade. Dissertação (Mestrado) Recife, PPGH/UFPE, 1994.

- Cenários de modernidade no Recife de princípios do século. V Seminário de história da cidade e do urbanismo. Campinas: PUC, 2001.

\section{Periódicos:}

DIÁRIO DE PERNAMBUCO. De uns e de outros. Coluna assinada pelo jornalista Aníbal Fernandes. Recife, p. 3, 11 jan. 1921.

JORNAL DO COMMERCIO. Recife, 20 de abril de 1921. Na polícia e nas ruas: pelos bons costumes.
Arquivo público Jordão Emerenciano. Recife, Pernambuco, p. 4, 20 abr. 1921.

JORNAL DO COMMERCIO. Recife, Pernambuco, 7 de janeiro de 1923. Arquivo público Jordão Emerenciano.

JORNAL DO COMÉRCIO. Recife, Pernambuco, 16 de agosto de 1923. Arquivo público Jordão Emerenciano.

JORNAL PEQUENO. Recife, 3 de maio de 1921. Arquivo público Jordão Emerenciano. RecifePernambuco, p. 12, 3 maio 1921.

A PROVÍNCIA. Recife, Pernambuco, 25 de maio de 1902. Arquivo público Jordão Emerenciano. 